\title{
How the Gender Gap Affects the Incidence and Prognosis of Cardiovascular Disease
}

\author{
Maria Gazzilli ${ }^{1}$ (1) \\ Nuclear Medicine - University of Brescia and Spedali Civili Brescia,' Brescia - Italy \\ Editorial Referring to the article: Closing the Gender Gap in Ischemic Heart Disease and Myocardial Infarction
}

The study in this issue of the Journal analyzed the sex and gender gap that exists for ischemic heart disease and myocardial infarction. The authors reviewed all the factors that differ between genders in terms of incidence, mortality, pathophysiology and clinical implications, diagnosis, and treatment. ${ }^{1}$

The article highlights firstly that there has been an increase in the annual change in proportional mortality from ischemic heart disease in women in recent years, with an age-standardized incidence of 104 per 100000 population for males and 58 per 100000 population for females. ${ }^{2-3}$

Although it is well known that there are important differences between men and women in the prevalence of risk factors for cardiovascular disease (CVD), studies have focused attention on older women with more comorbidities such as hypertension, dyslipidemia, diabetes, heart failure, and atrial fibrillation, demonstrating that smoking and diabetes mellitus have a more substantial impact on women. Moreover, postmenopausal hormonal changes play an important role in women's CVD. ${ }^{4-5}$

Further differences between men and women become apparent when considering the less common etiologies of cardiomyopathy. In fact, myocardial infarction with nonobstructive coronary arteries (MINOCA) is five times more likely to occur in women than in men as demonstrated by the VIRGO study. ${ }^{6}$

MINOCA occurs due to epicardial artery vasospasm, spontaneous coronary artery dissection, and Takotsubo syndrome, the last two conditions are common in young women. Tweet et al. ${ }^{7}$ demonstrated that

\section{Keywords}

Ischemic Heart Disease; Myocardial infarction. patients with MINOCA, especially women with microcirculatory dysfunction, had a poor prognosis related also to atypical symptoms, such as atypical chest pain, or associated symptoms, such as dyspnea, fatigue, sweating, and epigastric pain, thus leading to an incorrect diagnosis.

These differences in pathophysiology, clinical presentation and risk factors affect prognosis and treatment. The GUSTO study ${ }^{8}$ showed how women benefit more than men from primary angioplasty and have a poorer prognosis when fibrinolysis is the initial treatment of choice, because women have more strokes, heart failure, shock, bleeding, recurrent angina, and infarction than men when undergoing thrombolysis.

Furthermore, in non-ST elevation myocardial infarction (NSTEMI), although early revascularization is favorable, the elevated marker of myocardial necrosis is a challenge in women. Slagman et al. ${ }^{9}$ demonstrated that troponin had a lower positive predictive value and a slightly higher negative predictive value in women than in men.

As demonstrated by the DANAMI-3-PRIMULTI ${ }^{10}$ and Acute Compare trials, fractional flow reserve (FFR) is fundamental to the decision-making for revascularization; in fact, according to these studies, an FFR $<0.80$ suggests the need for revascularization, but the impact of this analysis is more significant when myocardial infarction occurs in women because they

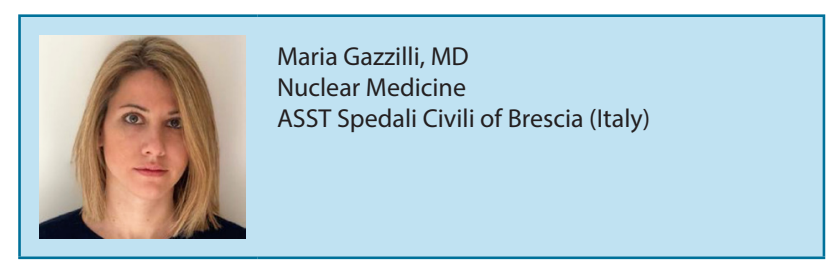

Mailing Address: Maria Gazzilli

Piazzale Spedali Civili, 1. Postal Code: 25123, Brescia - Italy.

E-mail: marinagazzilli@msn.com 
have a higher prevalence of microcirculatory dysfunction than men. In women, it is essential to consider the use of a functional assessment index of the microcirculation such as coronary flow reserve (CFR) and hyperemic microvascular resistance (HMR).

\section{References}

1. Ferreira MCM, Oliveira MV, Paiva MSM, Lemke V, Mangione F, Oliveira GMM. Closing the Gender Gap in Ischemic Heart Diseases and Myocardial Infarction. Int J Cardiovasc Sci. 2021; 34(4):471-483 doi: https://doi.org/10.36660/ijcs.20210001

2. Global Burden of Disease Study 2019 (GBD 2019) results. Global Health Data Exchange website. Seattle, WA: Institute for Health Metrics and Evaluation (IHME), University of Washington; 2019.

3. Oliveira GMM, Brant LCC, Polanczyk CA, Biolo A, Nascimento BR, Malta DC, et al. Cardiovascular statistics - Brazil 2020. Arq Bras Cardiol. 2020;115(3):308-439. doi: 10.36660/abc.20200812.

4. Haider A, Bengs S, Luu J, Osto E, Siller-Matula JM, Muka T, et al. Sex and gender in cardiovascular medicine: presentation and outcomes of acute coronary syndrome. Eur Heart J. 2020;41(13):1328-36. doi: 10.1093/ eurheartj/ehz898.

5. Rosano GM, Vitale C, Marazzi G, Volterrani M. Menopause and cardiovascular disease: the evidence. Climacteric. 2007;(10 Suppl 1):1924. doi: 10.1080/13697130601114917.

6. Safdar B, Spatz ES, Dreyer RP, Beltrame JF, Lichtman JH, Spertus JA, et al. Presentation, clinical profile, and prognosis of young patients
I invite you to read this article to understand all the mechanisms behind the gender gap in CVD and to discover how precision medicine must consider sex and age at a high level of decision-making to reach the correct diagnosis and treatment in CVD.

with Myocardial Infarction With Nonobstructive Coronary Arteries (MINOCA): results from the VIRGO study. J Am Heart Assoc. 2018;7(13):e009174. doi: 10.1161/JAHA.118.009174.

7. Tweet MS, Hayes SN, Pitta SR, Simari RD, Lerman A, Lennon RJ, et al. Clinical features, management, and prognosis of spontaneous coronary artery dissection. Circulation. 2012;126(5):579-88. doi: 10.1161/ CIRCULATIONAHA.112.105718.

8. Lee KL, Califf RM, Simes J, Van de Werf F, Topol EJ. Holding GUSTO up to the light. Global utilization of streptokinase and tissue Plasminogen activator for occluded coronary arteries. Ann Intern Med. 1994;120(10):876-81; doi: 10.7326/0003-4819-120-10-199405150-00009.

9. Slagman A, Searle J, Vollert JO, Storchmann H, Büschenfelde DM, von Recum J, et al. Sex differences of troponin test performance in chest pain patients. Int J Cardiol. 2015;187:246-51. doi: 10.1016/j.ijcard.2015.03.261.

10. Engstrøm T, Kelbæk H, Helqvist S, Høfsten DE, Kløvgaard L, Holmvang $\mathrm{L}$, et al. Complete revascularisation versus treatment of the culprit lesion only in patients with ST-segment elevation myocardial infarction and multivessel disease (DANAMI-3 - PRIMULTI): an open-label, randomised controlled trial. Lancet. 2015;386(9994):665-71. doi: 10.1016/ s0140-6736(15)60648-1. 